AperTO - Archivio Istituzionale Open Access dell'Università di Torino

\title{
BLOOD CONCENTRATION OF MARBOFLOXACIN AND ITS IN VIVO EFFECT IN YELLOW-BELLIED SLIDER TURTLES (TRACHEMYS SCRIPTA SCRIPTA), AFTER A SINGLE INTRACOELOMIC INJECTION AT THREE DOSE RATES
}

\section{This is the author's manuscript}

Original Citation:

Availability:

This version is available http://hdl.handle.net/2318/1585870

since 2018-04-05T19:23:13Z

Published version:

DOI:10.1053/j.jepm.2016.06.011

Terms of use:

Open Access

Anyone can freely access the full text of works made available as "Open Access". Works made available under a Creative Commons license can be used according to the terms and conditions of said license. Use of all other works requires consent of the right holder (author or publisher) if not exempted from copyright protection by the applicable law. 
This Accepted Author Manuscript (AAM) is copyrighted and published by Elsevier. It is posted here by agreement between Elsevier and the University of Turin. Changes resulting from the publishing process - such as editing, corrections, structural formatting, and other quality control mechanisms - may not be reflected in this version of the text. The definitive version of the text was subsequently published in JOURNAL OF EXOTIC PET

MEDICINE, Available online 30 June 2016 (In Press, Accepted Manuscript), 2016, 10.1053/j.jepm.2016.06.011.

You may download, copy and otherwise use the AAM for non-commercial purposes provided that your license is limited by the following restrictions:

(1) You may use this AAM for non-commercial purposes only under the terms of the CC-BY-NC-ND license.

(2) The integrity of the work and identification of the author, copyright owner, and publisher must be preserved in any copy.

(3) You must attribute this AAM in the following format: Creative Commons BY-NC-ND license (http://creativecommons.org/licenses/by-nc-nd/4.0/deed.en),

10.1053/j.jepm.2016.06.011

The publisher's version is available at:

http://linkinghub.elsevier.com/retrieve/pii/S1557506316300842

When citing, please refer to the published version.

Link to this full text:

http://hdl.handle.net/2318/1585870

This full text was downloaded from iris - AperTO: https://iris.unito.it/

iris - AperTO 


\section{Blood Concentration of Marbofloxacin and Its in vivo Effect in Yellow-Bellied Slider Turtles (Trachemys scripta scripta), After a Single Intracoelomic Injection at Three Dose Rates}

\section{Authors}

Cristina Vercelli,DVM, PhD, Virginia DeVito, Chem, Marco Salvadori, DVM, Raffaella Barbero, DVM, PhD, Giovanni Re, DVM, PhD, Dip. ECVPT, Maria Silvia Gennero, DVM, Mario Giorgi, Chem.

From the Department of Veterinary Sciences of Turin, Italy (Vercelli, Re), Department of Veterinary Medicine, University of Sassari, Italy (DeVito), Veterinary Exotic Center Exoticvet, San GiulianoTerme, Pisa, Italy (Salvadori), Section of Serology and Animal Welfare, Istituto Zooprofilattico Sperimentale Piemonte Liguria Valle d'Aosta, Turin, Italy (Barbero, Gennero), Department of Veterinary Sciences, University of Pisa, Italy (Giorgi). Address correspondence to Mario Giorgi, ChemD, SpecPharmacol, Department of Veterinary Sciences, University of Pisa, Via Livornese (lato monte), San Piero a Grado 56122, Pisa, Italy. Email address: mario.giorgi@unipi.it. Tel: 0039 (0)50 2210154. FAX: 0039 (0)50 2210182

\section{ABSTRACT}

Marbofloxacin is a commonly used antibiotic drug to treat bacterial infections in pet animals. Similarly to other fluoroquinolones, marbofloxacin is subject to the emerging problem of antimicrobial resistance. Thus, it is necessary to use PK/PD integration and modeling to minimize the selection of resistant mutants of bacteria and extend the useful life of antimicrobial agents, including marbofloxacin. This study evaluated the pharmacokinetics and the in vivo efficacy of marbofloxacin in Trachemys scripta scripta after a single intracoelomic injection. Three groups of 8 healthy adult turtles were each treated with $0.4,2$ and $10 \mathrm{mg} / \mathrm{kg}$ of marbofloxacin, respectively. Blood samples and rectal swabs were collected to measure marbofloxacin concentrations in serum (using an HPLC-FL validated method) and to evaluate in vitro antimicrobial susceptibility (using Kirby-Bauer Method), respectively. The PK profiles of marbofloxacin fit a bicompartmental model and were dose dependent. The Tmax and half life ranged between 2.82-4.64 hours and 16.14-30.68 hours, respectively. Bacteria isolation showed the presence of both E. coli and Salmonella spp. Salmonella spp. was isolated only 48 hours after the administration of marbofloxacin and all strains were considered resistant. Results seem to suggest that even if marbofloxacin is able to reach considerable plasma concentrations, it can still be ineffective against bacteria that are potential animal and human pathogens.

Key words: Marbofloxacin; pharmacokinetics; in vivo effect; turtles; antimicrobial resistance

\section{INTRODUCTION}

With the increasing popularity of herpetoculture, the treatment of bacterial infections in these animals should be based on a rational scientific approach. The most common pharmacokinetic/pharmacodynamic (PK/PD) approach for anti-microbial agents uses plasma concentration as the pharmacokinetic input value and minimum inhibitory concentration (MIC) as the pharmacodynamic input value.1 These are necessary to establish efficacious therapeutic treatment modalities that can augmented by a better understanding of these variables for the intended species.1 Marbofloxacin (M) is an antimicrobial agent belonging to the class of fluoroquinolones developed exclusively for veterinary use and differs from other fluoroquinolones because of its oxadiazine cycle. Marbofloxacin has a wide spectrum of bactericidal activity, mainly covering gram-negative pathogens including Pseudomonas spp., but it is also effective against some gram-positive pathogens such as Staphylococcus spp., and Mycoplasma spp.2 The proven efficacy and the valid pharmacodynamic and pharmacokinetic characteristics (i.e.: rapid bactericidal activity, wide spectrum of activity, large volume of distribution, low plasma protein binding, and relatively low minimal inhibitory concentrations (MICs) against target microorganisms) demonstrated in small and large mammals,3 has 
resulted in $\mathrm{M}$ commonly being used in an extra-label capacity for different animal species including reptiles.4 Significant inaccuracies may result when effects and consequences of drugs for the species of interest are predicted based on extrapolation from other species which have marked differences in their xenobiotic metabolism and physiological processes. 5 Obtaining data on treatment options is also important as chelonian species are becoming increasingly popular as pets (i.e.: in Europe and the USA). The last few decades have seen an increased interest in exotic animals, particularly reptiles and amphibians, as domestic pets. An estimated $1 \%$ of households in the USA and Europe are currently raising an exotic animal, and of these, turtles are the most commonly owned.6 Approximately 640,000 live reptiles are annually traded.7 Despite continuing efforts to regulate this global trade of live animals, illegal importation of wildlife species flourishes in developed countries and tortoises and semi-aquatic turtles are the most frequently purchased.8 Due to their rich and diverse microbiological biota, especially their propensity to act as carriers of Salmonella spp., these animals and their environments are potential reservoirs of infection, and are thought to have been responsible for numerous human salmonellosis outbreaks. A recent study suggests that annually, 74,000 cases of human salmonellosis in the United States are linked to reptile and amphibian exposure.9 These data are strictly connected to the emerging problem of antimicrobial resistance that involved several antibiotic drugs, including fluoroquinolones.1,10 Aside from the public health issues, these animals are considered as pets and are treated as members of the family, it follows that pet owners demand the same level of care they expect for themselves.11 The availability of specific, accurate, and targeted treatments is taken foregranted. Additionally, these animals represent a food source in some countries and for this reason; there is a need to determine the effects of xenobiotics entering the food chain through these animals. This is particularly important as reptiles are increasingly being used as a human food source (e.g. alligator meat, snakes, turtles, and turtle eggs). Considering all the aforementioned factors, the aim of the present study was to provide PK/PD data after single intracoelomic injection of $\mathrm{M}$ at 3 dose rates in yellow-bellied slider turtles (Trachemys scripta scripta).

\section{MATERIAL AND METHODS}

\section{Animal Treatment and Sampling}

Twenty-four clinically normal turtles (Trachemys scripta scripta) of both sexes (4 males, 20 females), with body weights ranging from 0.40 to $2.3 \mathrm{~kg}$ (mean $1.1 \mathrm{~kg}$ ), supplied by a local park, were used for the study. The turtles were acclimated for a 2-week period prior to commencement of the study. Turtles were judged to be in good health based on physical examination at the time of acquisition and at the start of the study, and through daily observation of behaviour and appetite. These observations were made by specialized veterinary personnel (M.S.). Animal care and handling was performed according to the provision of the EC council Directive 2010/63 and also according to Institutional Animal Care and Use directives issued by the Animal Welfare Committee of the University of Pisa, which approved the study protocol. Turtles were equally assigned to three treatment groups $(A, B$ and $C$, each $n=8)$ using 24 slips of paper marked with the numbers 1 to 24 in a box, according to a randomized, open, single-dose, three-treatment, one period, parallel study design. The proportions of sexes in each group were 2 males in group A and 1 male in group B and $C$. The 3 groups were placed in different $300 \mathrm{~L}$ plastic pools, with water depth of $25 \mathrm{~cm}$, water temperature of $25^{\circ} \mathrm{C}$, and custom-built mechanical and biological filtration. A dry basking area was heated to $30{ }^{\circ} \mathrm{C}$ using an infrared lamp. Ambient temperature in the room varied from 24 to $26{ }^{\circ} \mathrm{C}$ (electronic temperature sensors assured the constant temperature in both the water and basket area). Turtles were fed with a floating pelleted diet three times per week. Prior to use, injectable M (Marbocyl 1\%, Vetoquinol, UK) was diluted with saline in order to inject the same volume of drug per $\mathrm{kg}$ of animal, in the three groups. This was to reduce dosing errors due to the bias in small volume injections. Marbofloxacin was administered as a $0.4,2$, and $10 \mathrm{mg} / \mathrm{kg}$ bolus by intracoelomic injection in the left prefemoral fossa using a sterile 22-gauge $3.75 \mathrm{~cm}$ needle to group $A, B$, and C, respectively. Blood samples $(0.5 \mathrm{~mL}$ and $0.25 \mathrm{~mL}$ in subjects over or below $0.5 \mathrm{~kg}$ body weight, respectively) were collected from the dorsal cervical, 
subcarapacial venipuncture site at $0,0.5,4,10,24,48,72,96,120,144,168,192,216$ and $240 \mathrm{~h}$ after M administration. Although blood collected from the subcarapacial site can become contaminated by lymph, this was not considered an issue as fluoroquinolones have been reported to be equally distributed in blood and lymph as a result of their wide volume of distribution,12 the the pharmacokinetic data obtain should not have been affected. Blood was immediately transferred to tubes containing citric acid (Microtainer; Becton Dickinson and Company, Franklin Lakes, NJ USA), vortexed and stored at $-20^{\circ} \mathrm{C}$ until use within 30 days from collection. Sterile swabs were gently inserted in the first cloacal tract of each turtle daily $(0,24$, $48,72,96,120,144,168,192,216$, and $240 \mathrm{~h}$ ) after M administration. Swabs were immediately stored in sterile cryotubes (Nunc ${ }^{\circledR}$, Sigma Aldrich, St. Louis, MO USA) at $-80^{\circ} \mathrm{C}$ until the analyses was performed.

\section{Chemical and Reagents}

Pure $M$ and enrofloxacin (internal standard [IS]) powders (> 99.0\% purity) were purchased from SigmaAldrich (St. Louis, MO USA). High-performance liquid chromatography (HPLC) grade acetonitrile (ACN), dichloromethane $\left(\mathrm{CH}_{2} \mathrm{Cl} 2\right)$ and ethylacetate $(\mathrm{CH} 3 \mathrm{COOC} 2 \mathrm{H} 5)$ were purchased from Merck (Darmstadt, Germany). Tetraethyl amine was obtained from Sigma Chemical Co. (St Louis, USA). Phosphoric acid, sodium dihydrogenophosphate, disodium hydrogenophosphate heptahydrate and potassium dihydrogenophosphate were purchased from Carlo Erba (Milan, Italy). Deionised water was produced by a Milli-Q Millipore Water System (Millipore, MA USA). All the other reagents and materials were of analytical grade and supplied from commercial sources. The aqueous and organic components of the mobile phase, degassed under pressure, were mixed by the HPLC. The LC mobile phases were filtered through $0.2 \mu \mathrm{m}$ cellulose acetate membrane filters (Sartorius Stedim Biotech, Aubagne Cedex) with a solvent filtration apparatus. For bacterial isolation and identification, the following culture media were used: Xylose Lysine Deoxycholate Agar with Novobiocin $(X L D+N)$; Muller Kauffmann Tetrathionate broth with Novobiocin (MKTTn); Brilliant Green Agar (BGA); Triple Sugar Iron (TSI); Mueller-Hinton Agar (MH), these were purchased from Liofilchem (Roseto degli Abruzzi, Teramo, Italy). Marbofloxacin-impregnated disks for the Kirby Bauer method were obtained courtesy of ATI s.r.I. (Ozzano Emilia, Bologna, Italy).

\section{Preparation of Solutions}

Singular stock solutions of $\mathrm{M}$ and IS in water were prepared using dark volumetric flasks at an individual concentration of $1,000 \mu \mathrm{g} / \mathrm{mL}$, and subsequently stored at $+4{ }^{\circ} \mathrm{C}$. To reach the final concentration (100 $\mu \mathrm{g} / \mathrm{mL}$ ), appropriate dilutions of stock standard solutions were prepared diluting $1 \mathrm{~mL}$ of each solution to $10 \mathrm{~mL}$. The solution of $\mathrm{M}$ was then diluted in dark glass tubes $(10 \mathrm{~mL})$ to reach final concentrations of 10,5 and $1 \mu \mathrm{g} / \mathrm{mL}$. These were stored at $+4{ }^{\circ} \mathrm{C}$. This latter concentration $(1 \mu \mathrm{g} / \mathrm{mL})$ was then diluted to prepare a five-point calibration curve of the analytes at the following concentrations: $0.200,0.100,0.050,0.025$, and $0.010 \mu \mathrm{g} / \mathrm{mL}$. The $\mathrm{M}$ solution was stable for at least 10 weeks if stored at $+4{ }^{\circ} \mathrm{C}$.

\section{Instrumentation and Chromatographic Conditions}

The HPLC system was an LC system (Jasco, Japan) consisting of a high pressure mixer pump (model PU 980 Plus), spectrofluorometric detector (model 2020 Plus) and a loop of $50 \mu \mathrm{L}$. Data was processed using Borwin software (Jasco, Inc.). Chromatographic separation assay, modified from Giorgi et al. (2013) was performed by a Sinergy polar RP $80 \mathrm{~A}$ analytical column $(150 \times 4.6 \mathrm{~mm}$ inner diameter, $4 \mu \mathrm{m}$ particle size, Phenomenex, Torrance, CA USA) maintained at $25^{\circ} \mathrm{C}$. The mobile phase consisted of ACN: aqueous solution $(20: 80 \mathrm{v} / \mathrm{v} \%)$ at a flow rate of $1 \mathrm{~mL} / \mathrm{min}$. The aqueous solution consisted of potassium dihydrogenphosphate $(0.02 \mathrm{M})$, phosphoric acid $(0.006 \mathrm{M})$ and tetraethyl amine $(0.012 \mathrm{M})$ in water. Excitation and emission wavelengths were set at 295 and $500 \mathrm{~nm}$, respectively.

\section{Sample Extraction}


The procedure was based on that previously reported by Giorgi, et al12, with slight modifications. Briefly, aliquots $(0.2 \mathrm{~mL})$ of blood were added to $0.1 \mathrm{~mL}$ of IS $(500 \mathrm{ng} / \mathrm{mL})$ and diluted with $800 \mu \mathrm{L}$ of $0.1 \mathrm{M}$ phosphate buffer at $\mathrm{pH} 7.4$. After adding $6 \mathrm{~mL}$ of a mixture of $\mathrm{CH} 2 \mathrm{Cl} 2$, the samples were shaken at 200 oscillations/minutes, for 10 minutes and centrifuged at 4,000 g for 5 minutes. Five $\mathrm{mL}$ of the organic layer was transferred into a clean tube and dried at $40{ }^{\circ} \mathrm{C}$ under nitrogen stream. The residue was dissolved in $0.2 \mathrm{~mL}$ mobile phase, vortexed and an aliquot was injected into the chromatographic system.

\section{Quantification}

Standard curves were constructed with standard $M$ concentrations vs. ratio of $M /$ internal standard peak areas. Linearity of the regression curve was assessed on the basis of the residual plot, the fit test and the back calculation (within $20 \%$ of known amount). The quantitative HPLC method was validated by examining the measurement of consistency of results (within-run and between-run), correlation (coefficient of determination of the standard curve), and extraction efficiency of the assay. The within-run precision was calculated from similar responses from six repeats of three control samples $(10,100$, and $200 \mathrm{ng} / \mathrm{mL})$ in one run. The between-run precision was determined by comparing the calculated response (in $\mathrm{ng} / \mathrm{mL}$ backfit of the standard curve) of the low $(10 \mathrm{ng} / \mathrm{mL})$, middle $(100 \mathrm{ng} / \mathrm{mL})$, and high $(200 \mathrm{ng} / \mathrm{mL})$ control samples over three consecutive daily runs (total of six runs). The assay accuracy for within-run and between-run was established by determining the ratio of calculated response to expected response for low $(10 \mathrm{ng} / \mathrm{mL})$, middle $(100 \mathrm{ng} / \mathrm{mL})$, and high $(200 \mathrm{ng} / \mathrm{mL})$ control samples over six runs. The extraction efficiency was determined by comparing the response (in area) of low, middle, and high standards, and the internal standard, spiked into blank plasma eluent before evaporation, to the response from equivalent extracted standards.

\section{Bacteria Isolation and marbofloxacin Efficacy}

Samples were examined with a four-step procedure: pre-enrichment, enrichment, selective and differential culture media and identification. The swabs with cloacal or faecal materials were subjected to preenrichment; each sample was soaked in $9 \mathrm{~mL}$ of buffered peptone water (BPW) medium for $30 \mathrm{~s}$, and then stored at $-20^{\circ} \mathrm{C}$. The BPW was incubated at $37 \pm 1{ }^{\circ} \mathrm{C}$ for $18 \pm 2 \mathrm{~h}$. The enrichment step used $100 \pm 10 \mathrm{~mL}$ of BPW dispersed in $10 \pm 0.5 \mathrm{~mL}$ of Müller Kauffmann tetrathionate broth with novobiocin (MKTTn), this was incubated at $37 \pm 2{ }^{\circ} \mathrm{C}$ for $24 \pm 3 \mathrm{~h}$. One $\mathrm{mL}$ of colony material from the opaque zone of the colonies was streaked on Xylose Lysine Deoxycholate agar with novobiocin (XLD + N) and Brilliant Green Agar (BGA) using a sterile disposable loop, and incubated at $37 \pm 2{ }^{\circ} \mathrm{C}$ for $24 \pm 2 \mathrm{~h}$. Colonies suspected to be Salmonella spp. on the XLD $+\mathrm{N}$ and/or BGA plates were inoculated into Triple Sugar Iron (TSI) and incubated at $37{ }^{\circ} \mathrm{C}$ for $24 \mathrm{~h}$. Identification was performed using a commercial micromethod (API $20 \mathrm{E}$; BioMerieux, Rome, Italy).

\section{In vitro Antimicrobial Susceptibility Test}

Each strain was analyzed to evaluate the antimicrobial susceptibility following the Kirby Bauer method (Bauer et al., 1966) described in Clinical and Laboratory Standards Institute (CLSI) guidelines.13 Using a sterile inoculating loop or needle, material was collected from four or five isolated colonies of organisms; the colonies were then suspended in $2 \mathrm{~mL}$ of sterile saline solution and the tube was vortexed to create a smooth suspension (adjusting the turbidity to $0.5 \mathrm{McFarland}$ standards). A sterile swab was dipped into the inoculum solution and rotated against the side of the tube using firm pressure, to remove the excess fluid. Mueller-Hinton Agar was inoculated by streaking the swab three times over the entire dried surface of the agar. Appropriate antimicrobial-impregnated disks were placed on the surface of the agar, using forceps to dispense each antimicrobial disk one at a time. Then, all plates were incubated at $37^{\circ} \mathrm{C}$ for 18 hours. KirbyBauer test protocol provides for the measurement of inhibition zone of microbial growth around the disk. Using a caliper, each zone was measured with the unaided eye while viewing the back of Petri dish. In particular, the pharmacological activity of $\mathrm{M}$ against different bacteria was tested. On the recording sheet, 
depending on the inhibition zone size, the strain was classified as susceptible ( $\mathrm{S} ;>18 \mathrm{~mm}$ ), intermediate (l; $14<X<18 \mathrm{~mm})$, or resistant $(R ;<14 \mathrm{~mm})$, compared to the reference values.

\section{Statistical Analysis and Pharmacokinetic Evaluation}

The animal sample size was determined for a study with a $80 \%$ power, a $\mathrm{P}<0.05$ and a standard deviation of about $30 \%$ as averaged by former similar studies in turtles.12,14 Marbofloxacin plasma concentration versus time curves were modeled for each subject using a mono- or a two-compartment open model with different weighing factors $(1,1 / c, 1 / c 2) .15$ Comparison between competing models was made using the random distribution residuals, visual inspection of the goodness of fit curves and the Akaike's information criterion. The pharmacokinetic calculations were carried out using WinNonlin v 5.3.1 (Pharsight Corp, Sunnyvale, CA, USA). The results obtained from the Kirby-Bauer isolation test were organized and analysed using Prism 5.0 software (Graph Pad). Normality was evaluated using Shapiro-Wilk test and data were elaborated using One-way Anova with Dunnet post test, assuming a significant value at $P<0.05$.

\section{$\underline{\text { RESULTS }}$}

\section{Animals}

Two days after the treatment, 2 turtles belonging to the highest dose group died. Apart from this, other animals did not demonstrate visible local or systemic adverse effects. Until the time of an animals death, blood samples and cloacal swabs were collected as required by study protocol.

\section{Pharmacokinetics}

The PK profiles of M, fitted by a bi-compartmental model, were dose dependent, showing Cmax and AUC values increasing proportionally with the increasing dose (Table 1). The ranges of Tmax and half life were quite variable, $2.82-4.64$ hours and $16.14-30.68$ hours, respectively. Marbofloxacin was quantifiable in the three treatment groups from the first collection time ( 0.5 hours) to 144 hours although not in all the animals. The three averaged curves were parallel up to 96 hours, then the $0.4 \mathrm{mg} / \mathrm{kg}$ group deviated. The plasma concentration versus time curves are reported in Figure 1.

\section{Kirby-Bauer Isolation Test}

Escherica. coli was isolated in all the groups at TO. The mean of the zone of inhibition against E. coli was $35.4 \pm 0.6 \mathrm{~mm}, 36.0 \pm 0.9 \mathrm{~mm}$, and $36.5 \pm 0.9 \mathrm{~mm}$, for Groups A, B, and C, respectively. According to the CLSI guidelines, data indicated the bacteria were sensitive to $M$. No bacteria were isolated in any of the groups at T24 hours. Beginning at T48 hours, strains of Salmonella spp. were identified with all of these bacterial isolates having an inhibition zone close to $0 \mathrm{~mm}$, indicating a strong resistance to $\mathrm{M}$. In group $\mathrm{B}$ only, two strains of E. coli resistant to $M$ were isolated at T $96 \mathrm{~h}$. Figure 2, 3, and 4 represent the results concerning the bacterial isolation in different groups at all time points. Figure 5 summarizes the total amount of each species of bacteria isolated during the present study: the majority of the isolated bacteria (26/36) were Salmonella spp. resistant to M. Figure 6 shows the comparison between the bacteria isolated at each experimental time point and for each treatment group. One way Anova highlighted a statistically significant difference $(P<0.05)$ was observed between group $A$ at T96 hours versus the other groups and experimental time points. Group A at this time point demonstrated the largest amount of bacteria, all of which were resistant to $\mathrm{M}$.

\section{DISCUSSION}

The aim of the present study was to evaluate the pharmacokinetics of $M$ in yellow-bellied slider turtles (Trachemys scripta scripta) and to integrate these data with pharmacodynamic parameters concerning M's influence on populations of cloacal bacteria. The PK data obtained in the present study established that intracoelomic injection at $0.4,2$, and $10 \mathrm{mg} / \mathrm{kg}$ were all detectable 5 minutes after the drug administration. 
Drug was detectable in each single animal at different ranges of time, showing a large intergroup variability. The large variability in pharmacokinetic values in wild animals has been previously reported.12,14 However, it might have been exacerbarted by the randomized grouping of the animals that did not consider the sex, weight, and age of the test subject. At 120 hours after the drug administration, animals in group $A$ showed an increase in plasma concentration. Several factors might have contributed to this unexpected result: $i)$ the small number $(n=6)$ of animals showing quantifiable concentrations of $M$ close to the LOD of the method; ii) damage to the water filtration/recycling system of the pool where the animals were placed; iii) other undocumented factors. The calculation of AUC and Cmax demonstrated concentration dependent behavior, according to the increasing dose administered to different groups. This was also demonstrated in previous research.16 Considering the route of administration, some authors claimed that oral treatment is the most suitable route of administration in turtles.17,18 However, oral administration requires either pharyngostomy tube placement or potentially uncomfortable head restraint. These two options can cause pain to the animals and, the latter technique in particular, can be stressful to the animal, especially in small turtles. Some studies involving fluoroquinolones injected via the intramuscular route in reptiles, reported that local irritation and soft tissue necrosis can occur through this route of administration.17-20 It has been recently reported that intracelomic administrations of diluted fluoroquinolones have not shown the above mentioned adverser no localized adverse side effects were observed in the present study. For these reasons, in the present study the intracelomic route was used as it was considered more reproducible and suitable in terms of animal welfare. The pharmacokinetic analysis showed that the $\mathrm{Cmax}$ at the clinical dosing $(2 \mathrm{mg} / \mathrm{kg}$ ) was slightly higher and drastically lower than those reported in mammals 21 and in Caretta caretta turles2 respectively, after IM administrations. Considering turtle species are more closely related to one another than to other orders of animals, this wide variation underlies the importance of conducting pharmacokinetic studies for individual species rather than extrapolating or transposing doses from data generated in other species.22 Two turtles of the highest dose group died two days after $\mathrm{M}$ administration. Samples were collected up to the time of death and did not demonstrate any particular abnormalities. Only physical examination was performed and no necropsy evaluation done on these subject turtles. In the authors' opinion, it is not possible to assume that the death of these animals was triggered by the high dose administration of $\mathrm{M}$. Indeed, Shan et al.16 reported that when a dosage of $10 \mathrm{mg} / \mathrm{kg}$ was administered, both orally and intramuscularly, in soft shelled turtles, the only side effects noted were transient and uncommon. The same dose regimen was also administered to cattle and similarly in this study, no toxic or lethal effects were seen. 3 The dose of $10 \mathrm{mg} / \mathrm{kg}$ of $M$ was administrated subcutaneously in koalas (Phascolarctos cinereus), and no toxic effects were reported although there was an increase in creatinkinase levels in blood samples collected after the administration.23 Nevertheless, further, more directed studies should be performed to evaluate potential toxicity at such a high dosage, especially in chelonian species. The data obtained from bacterial isolation showed that at T0, only E.coli colonies were identified. Eschericia coli is normally present in cloacal or fecal samples, all of these were sensitive to the effect of $\mathrm{M}$. In the authors' opinion, no other bacteria were isolated because the burden of $\mathrm{E}$. coli was very high, and they would overgrow any other bacteria. After a short period where no bacteria were isolated, 48 hours after $\mathrm{M}$ administration, Salmonella spp. was isolated from all groups. Likely, these data suggest a good sensitivity to the $\mathrm{M}$ of E. coli normally present in cloaca. Eschericia coli, competes, as is known, with other bacteria for growth and living spaces at the level of the enteric microbiome. However, in this study, it is clear that the selective pressure of $\mathrm{M}$ eliminated $\mathrm{E}$. coli, thereby enabling the growth and selection of $\mathrm{M}$ resistant Salmonella spp. From their initial isolation, these bacteria demonstrated a strong resistance to $M$. This resistance was maintained for all the subsequent time points until the end of the experiment. The experimental time point of T96 $\mathrm{h}$ in Group A demonstrated a statistically significant difference $(P<0.05)$ vs. all the other time points: the elevated number of isolates and the global resistance of the isolated bacteria seemed to suggest that a low concentration of $\mathrm{M}$ could be well tolerated by common bacteria, leading to the development of antibiotic resistance. These results are in line with a previous study on dogs showing that $M$ was not able to eradicate Staphylococcus intermedius in Beagle dogs, 21 but conflicting with a 
recent study performed in soft shelled turtles,16 where $M$ was demonstrated to have a bactericidal/bateriostatic action against Aeromonas hydrophilia. To the best of authors' knowledge, no other studies have evaluated E. coli and Salmonella spp. in vivo, in turtlesnor in other animal species. Only the article by Andraud, et al24 evaluated the antimicrobial effects of $\mathrm{M}$ using a pharmacodynamic in vitro model using swine fecal samples. The authors calculated several parameters and confirmed that the behavior of $\mathrm{M}$ is concentration-dependent, but the killing effect significantly dependents on duration of exposure.24 This last result partially supports the results of the present study, in which E. coli was isolated only at the first time point in all groups, and disappeared after drug administration. The difference between the two studies was that in Group A (treated with $0.2 \mathrm{mg} / \mathrm{mL}$ ) in the present study, at 96 hours, two colonies of $\mathrm{E}$. coli were isolated and were resistant to $\mathrm{M}$. The development of antimicrobial resistance in recent decades has led to an intensification of discussion about the prudent use of antimicrobial agents, both in veterinary and human medicine. The consumption of several antimicrobials, extensively used in animal husbandry, was higher in animals than in humans, while consumption of antimicrobials critically important (CIA) for human medicine (e.g., fluoroquinolones, 3rd and 4th generation cephalosporins) was higher in humans.10 In both humans and animals, positive associations between consumption of antimicrobials and the corresponding resistance in bacteria were observed in most cases. Although in vitro susceptibility testing remains the cornerstone of clinical antibacterial therapy, not all naturally occurring mechanisms of resistance can be detected by standard laboratory methodologies. At the end of the '80s, Sanders et al.25 reported that bacterial resistance during cephalosporin treatment developed in some 20$40 \%$ of systemic infections with Gram-negative bacilli, accounting for treatment failure or relapse in at least $10 \%$ of such cases. In those years, hospital antibiograms reported $75-90 \%$ of E. cloacae and S. marcescens isolates to be susceptible to third-generation cephalosporins. In the next years, the same pathogens may acquire an antibiotic resistance, leading to an increase of treatment failure. It seems clear that without accurate laboratory detection and investigation regarding occult resistance phenotypes, the treatment of Gram-negative infections may remain suboptimal.26 The long lasting pharmacokinetics of $M$ in turtles, highlighted in previous studies and confirmed in the present paper, has other ramifications. In many Eastern cultures, turtles are part of the human food chain.27 Consumption of turtle meats containing antibiotic residues could facilitate the rapid development of resistant bacteria in humans. This situation has been already emphasised in the "classical" food producing animals where the antimicrobial agents such as 3rd- and 4th-generation cephalosporins, fluoroquinolones, and macrolides are widely prescribed (accounted for $0.2 \%, 1.7 \%$ and $8 \%$, respectively, of the total sales of drugs in 26 countries of European Union. 28 Hence it is important to study the pharmacokinetics and pharmacodynamics of antibiotics in each animal species. It is well known that dose or efficacy extrapolation from other animal species can lead to shortcomings. This is particularly true when the estrapolation occurs between species with marked differences in xenobiotic metabolism and physiological processes (i.e. mammals vs. reptiles).

\section{CONCLUSION}

In conclusion, even if $\mathrm{M}$ is able to reach quickly detectable concentrations in turtle plasma, the efficacy against bacteria isolated in cloacal swabs was not optimal. Moreover, the isolated bacteria demonstrated a strong resistance to $M$. The results of the present study seem to suggest that the use of $M$ for therapeutic purposes should be carefully considered, not only taking into account the low efficacy but also for the risk to induce antibiotic resistance in bacteria that could be potentially pathogenic for humans.

\section{ACKNOWLEDGEMENTS}

This work was equally supported by athenaeum funds (ex $60 \%$ Univeristy of Pisa and Fondi per la Farmacorigilanza Regione Piemonte). No external funding was used to support the preparation of manuscript. Authors acknowledge Dr. H. Owen, University of Queensland, Australia for the English and scientific editing of the manuscript. 


\section{REFERENCES}

1. Liu H, Liu X, Li Y, et al: Effect of six fluoroquinolones on the expression of four efflux pumps in the multidrug resistant Escherichia coli isolates. World J Micro Biotech 31:1041-1048, 2015

2. Lai OR, Marín P, Laricchiuta P, et al: Pharmacokinetics of marbofloxacin in loggerhead sea turtles (Caretta caretta) after single intravenous and intramuscular doses. J Zoo Wildlif Med 40:501-507, 2009

3. Grandemange E, Fournel S, Giboin $\mathrm{H}$, et al: Efficacy of a single injection of marbofloxacin in the treatment of bovine respiratory disease. Revue De Med Vet 163:287-294, 2012

4. Marín PA, Lai OR, Laricchiuta P, Marzano G., et al: Pharmacokinetics of marbofloxacin after a single oral dose to loggerhead sea turtles (Caretta caretta). Res Vet Sci 87:284-286, 2009

5. Toutain PL, Ferran A, Bousquet-Melou A: Species differences in pharmacokinetics and pharmacodynamics, in Cunningham F, Elliott J, Lees P (eds): Comparative and Veterinary Pharmacology. Berlin, Springer-Verlag pp 19-48, 2010

6. Harris JR, Neil KP, Behravesh CB, et al: Recent multi state outbreaks of human

Salmonella spp. infections acquired from turtles: a continuing public health challenge. Clin Infect Dis 50:554-559, 2010

7. Karesh WB, Cook RA, Bennett EL, et al: (2005) Wildlife trade and global disease. Emerg Infect Dis 11:1000-1002, 2005

8. Nowakiewicz A, Ziółkowska G, Zieba P, et al: (2012) Russian tortoises (Agrionemys horsfieldi) as a potential reservoir for Salmonella spp. Res Vet Scien 92:187-190, 2012

9. Mermin J, Hutwagner L, Vugia D, et al: Reptiles, amphibians, and human Salmonella infection: a population-based case- control study. Clin Infect Dis 38:253-261, 2004

10. WHO Experts Advisory Group on Integrated Surveillance of Antimicrobial Resistance Critically Important Antimicrobials, 3rd meeting report, 2011

11. Hofman J, Perkins C: Veterinary generics: an enigma among niche markets. J Gener Med 5:281-289, 2008

12. Giorgi M, Rota S, Giorgi T, et al: Blood concentrations of enrofloxacin and the metabolite ciprofloxacin in yellow-bellied slider turtles (trachemys scripta scripta) after a single intracoelomic injection of enrofloxacin. J Exot Pet Med 22:192-199, 2013

13. Bauer AW, Kirby MM, Sherris JC, et al: (1966) Antibiotic susceptibility testing by a standardized single disk method. Am J Clin Path 45:493-496, 1966

14. Salvadori $M$, De Vito $\mathrm{V}$, Owen $\mathrm{H}$, et al: Pharmacokinetics of enrofloxacin and its metabolite ciprofloxacin after intracoelomic administration in Tortoises (Testudo hermanni). Israel J Vet Med 70:45-48, 2015

15. Gibaldi M, Perrier D: Pharmacokinetics (ed 2). New York, NY, Ed Marcel Dekker, 1982

16. Shan $Q$, Zheng G, Liu S, et al: Pharmacokinetic/pharmacodynamic relationship of marbofloxacin against Aeromonas hydrophila in Chinese soft-shelled turtles (Trionyx sinensis). J Vet Pharm Therap doi: 10.1111/jvp.12214. in press

17. James SB, Calle PP, Raphael BL, et al: Comparison of injectable versus oral enrofloxacin pharmacokinetics in red-eared slider turtles, Trachemys scripta elegans. J Herp Med Surg 13:5-10, 2003 
18. Jacobson E, Gronwall R, Maxwell L, et al: Plasma concentrations of enrofloxacin after single-dose oral administration in loggerhead sea turtles (Caretta caretta). J Zoo Wildlif Med 36:708-712, 2005

19. Maxwell LK, Jacobson ER: Preliminary single-dose pharmacokinetics of enrofloxacin after oral and intramuscular administration in green iguanas (Iguana iguana). Proc Am Assoc Zoo Vet, Puerto Vallarta, Mexico p 25, 1997

20. Young LA, Schumacher J, Papich MG, et al: (1997) Disposition of enrofloxacin and its metabolite ciprofloxacin after IM injection in juvenile Burmese pythons (Python molurus bivittatus). J Zoo Wildlif Med 28:71-79, 1997

21. Yohannes S, Awji EG, Lee SJ, et al: Pharmacokinetics and pharmacokinetics/pharmacodynamic integration of marbofloxacin after intravenous and intramuscular administration in beagle dogs. Xenobio 45:264-269, 2015

22. Isazar R, Jacobson ER: Antimicrobial drug use in reptiles, in Giguere S, Prescott JF, Dowling PM (eds): Antimicrobial Therapy in Veterinary Medicine (ed 5): Ames, IA, Wiley-Blackwell pp.623-636, 2013

23. Griffith JE, Higgins DP, Li KM, et al: Absorption of enrofloxacin and marbofloxacin after oral and subcutaneous administration in diseased koalas (Phascolarctos cinereus). J Vet Pharm Therap 33:595-604, 2010

24. Andraud $M$, Chauvin $C$, Sanders $P$, et al: Pharmacodynamic modeling of in vitro activity of marbofloxacin against Escherichia coli strains. Antimicrob Agents Chemoth 55:756-761, 2011

25. Sanders WE Jr, Sanders CC: Inducible beta-lactamases: clinical and epidemiologic implications for use of newer cephalosporins. Arch - Clin Infect Dis 10:830-838, 1988

26. Ertl RP, Winston GW: The microsomal mixed function oxidase system of amphibians and reptiles: components, activities and induction. Comp Biochem Phys - Part C: Toxico Pharm 121:85-105, 1998

27. Qin X, Weissman SJ, Chesnut MF, et al: Kirby-Bauer disc approximation to detect inducible thirdgeneration cephalosporin resistance. Enterobacteriaceae. Ann Clin Microbio Antimicro 3:13, 2004

28. European Surveillance of Veterinary Antimicrobial Consumption (ESVAC) 4th Report, 2012, Sales of veterinary antimicrobial agents in 26 EU/EEA countries in 2012. 
Table 1

Main pharmacokinetic parameters after intracoelomic administrations of marbofloxacin at $0.4,2$ and 10 $\mathrm{mg} / \mathrm{kg}$ in turtles (Trachemys scripta scripta).

\begin{tabular}{|c|c|c|c|c|c|c|c|c|c|c|}
\hline \multirow[b]{2}{*}{ Parameters } & \multirow[b]{2}{*}{ Units } & \multicolumn{3}{|c|}{$\begin{array}{c}\text { Group I } \\
(0.4 \mathrm{mg} / \mathrm{kg})\end{array}$} & \multicolumn{3}{|c|}{$\begin{array}{l}\text { Group II } \\
(2 \mathrm{mg} / \mathrm{kg})\end{array}$} & \multicolumn{3}{|c|}{$\begin{array}{l}\text { Group III } \\
(10 \mathrm{mg} / \mathrm{kg})\end{array}$} \\
\hline & & Mean & & SD & Mean & & SD & Mean & & SD \\
\hline $\mathrm{AUC}_{0-\infty}$ & hr*ng/mL & 4697.60 & \pm & $2770: 84$ & 16257.72 & \pm & 6066.75 & 139146.00 & \pm & 38097.94 \\
\hline K01 HL & $\mathrm{hr}$ & 1.14 & \pm & 1.51 & 1.24 & \pm & 1.00 & 1.96 & \pm & 1.10 \\
\hline $\mathrm{K} 10 \mathrm{HL}$ & $\mathrm{hr}$ & 10.48 & \pm & 5.58 & 6.90 & \pm & 3.74 & 8.84 & \pm & 4.79 \\
\hline Alpha HL & $\mathrm{hr}$ & 6.42 & \pm & 4.64 & 3.14 & \pm & 1.13 & 3.73 & \pm & 2.51 \\
\hline Beta HL & $\mathrm{hr}$ & 30.68 & \pm & 20.26 & 24.94 & \pm & 11.32 & 16.14 & \pm & 3.61 \\
\hline $\mathrm{CL} / \mathrm{F}$ & $\mathrm{mL} / \mathrm{hr} / \mathrm{kg}$ & 116.77 & \pm & 72.52 & 141.62 & \pm & 62.68 & 76.78 & \pm & 24.46 \\
\hline $\mathrm{V} / \mathrm{F}$ & $\mathrm{mL} / \mathrm{kg}$ & 1590.37 & \pm & 1471.61 & 1525.01 & \pm & 1170.73 & $468: 46$ & \pm & 462.07 \\
\hline Tmax & $\mathrm{hr}$ & 3.45 & \pm & 3.62 & 2.82 & \pm & 1.22 & 4.64 & \pm & 2.06 \\
\hline Cmax & $\mathrm{ng} / \mathrm{mL}$ & 235.36 & \pm & 44.03 & 1047.61 & \pm & 272.21 & 7145.83 & \pm & 3493.64 \\
\hline K01 & $1 / \mathrm{hr}$ & 2.33 & \pm & 2.25 & 0.90 & \pm & 0.55 & 0.48 & \pm & 0.31 \\
\hline K10 & $1 / \mathrm{hr}$ & 0.09 & \pm & 0.06 & 0.13 & \pm & 0.06 & 0.11 & \pm & 0.08 \\
\hline $\mathrm{K} 12$ & $1 / \mathrm{hr}$ & 0.07 & \pm & 0.08 & 0.08 & \pm & 0.04 & 0.09 & \pm & 0.11 \\
\hline $\mathrm{K} 21$ & $1 / \mathrm{hr}$ & 0.05 & \pm & 0.02 & 0.07 & \pm & 0.04 & 0.11 & \pm & 0.04 \\
\hline
\end{tabular}




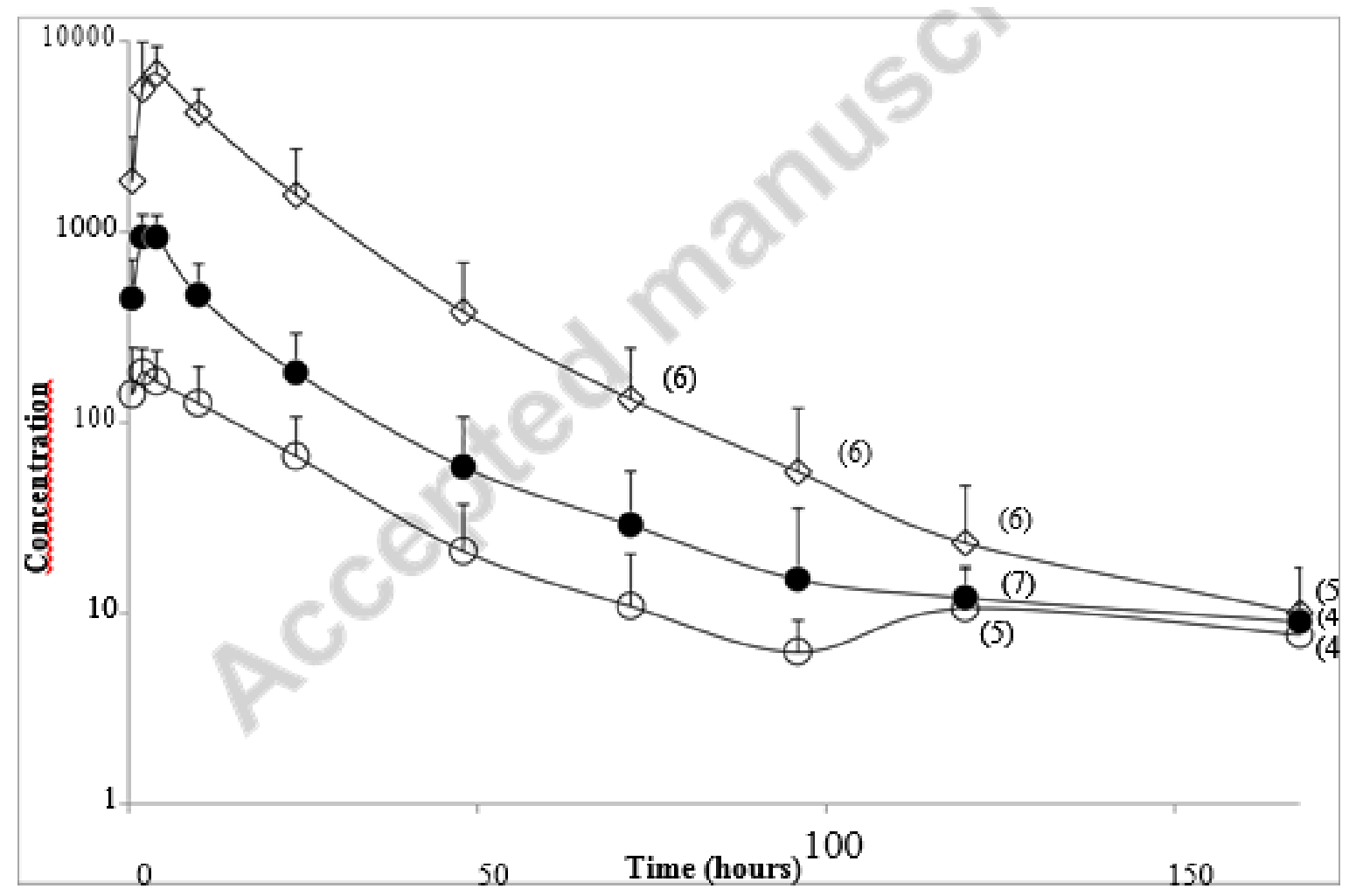

Fig. 1. Observed mean plasma concentrations of marbofloxacin after intracoelomic injection of 0.4 $\mathrm{mg} / \mathrm{kg}\left({ }^{\bigcirc}, \mathrm{n}=8\right), 2 \mathrm{mg} / \mathrm{kg}\left({ }^{\bullet}, \mathrm{n}=8\right)$ and $10 \mathrm{mgkg}\left({ }^{\diamond}, \mathrm{n}=8\right)$ in turtles (Trachemys scripta scripta). Bars represent standard error of the mean. Numbers in the brackets indicate the number of values used to calculate each mean value, if different from 8 . 


\section{Kirby Bauer Group A $(0.4$ mg/kg)}

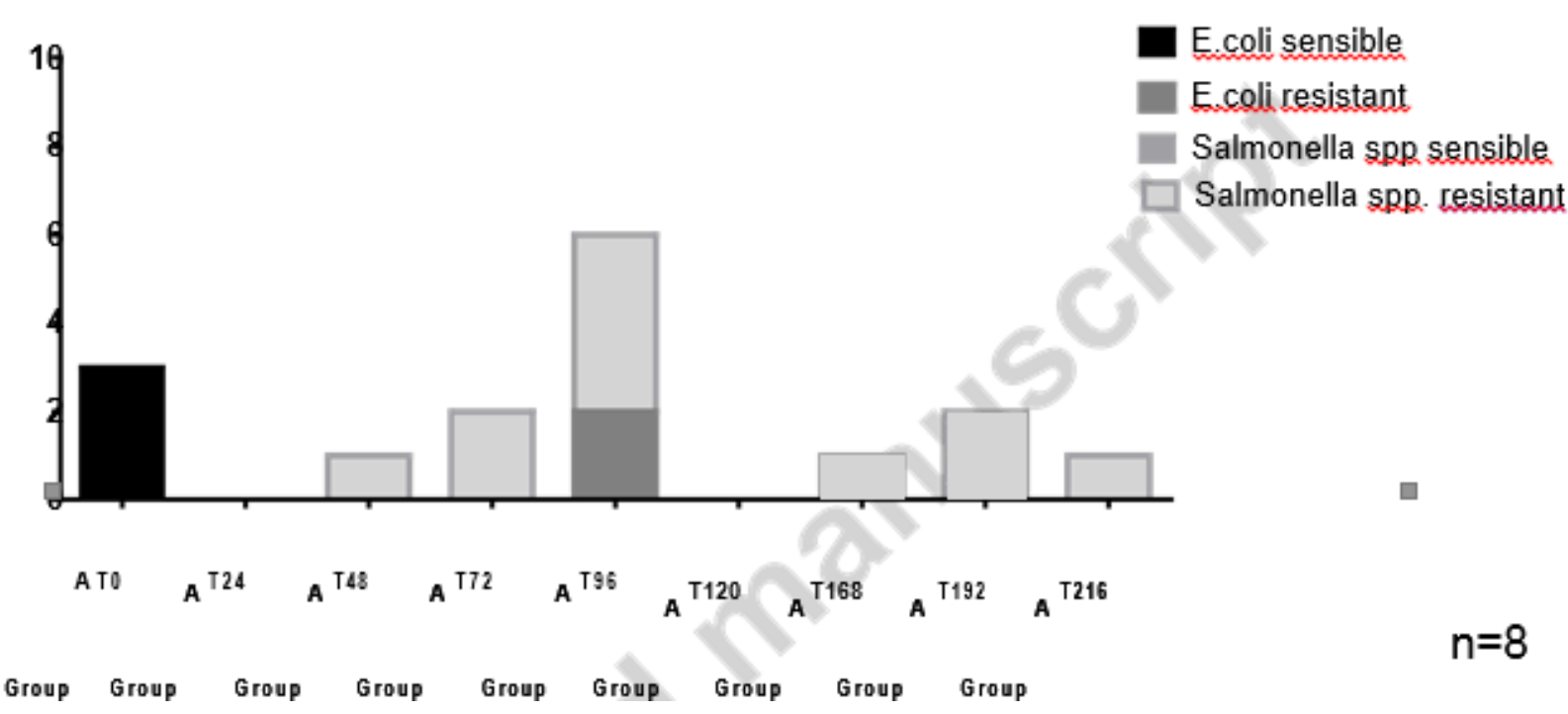

Fig.2: Distribution of isolated bacteria from cloacal swabs after single intracelomic administration of $0.4 \mathrm{mg} / \mathrm{kg}$ (Group A) of marbofloxacin in turtles (Trachemis scripta scripta). Bacterial sensitivity or resistance to marbofloxacin was test using Kirby - Bauer method $(n=8)$. 


\section{Kirby Bauer Group B (2mg/kg)}

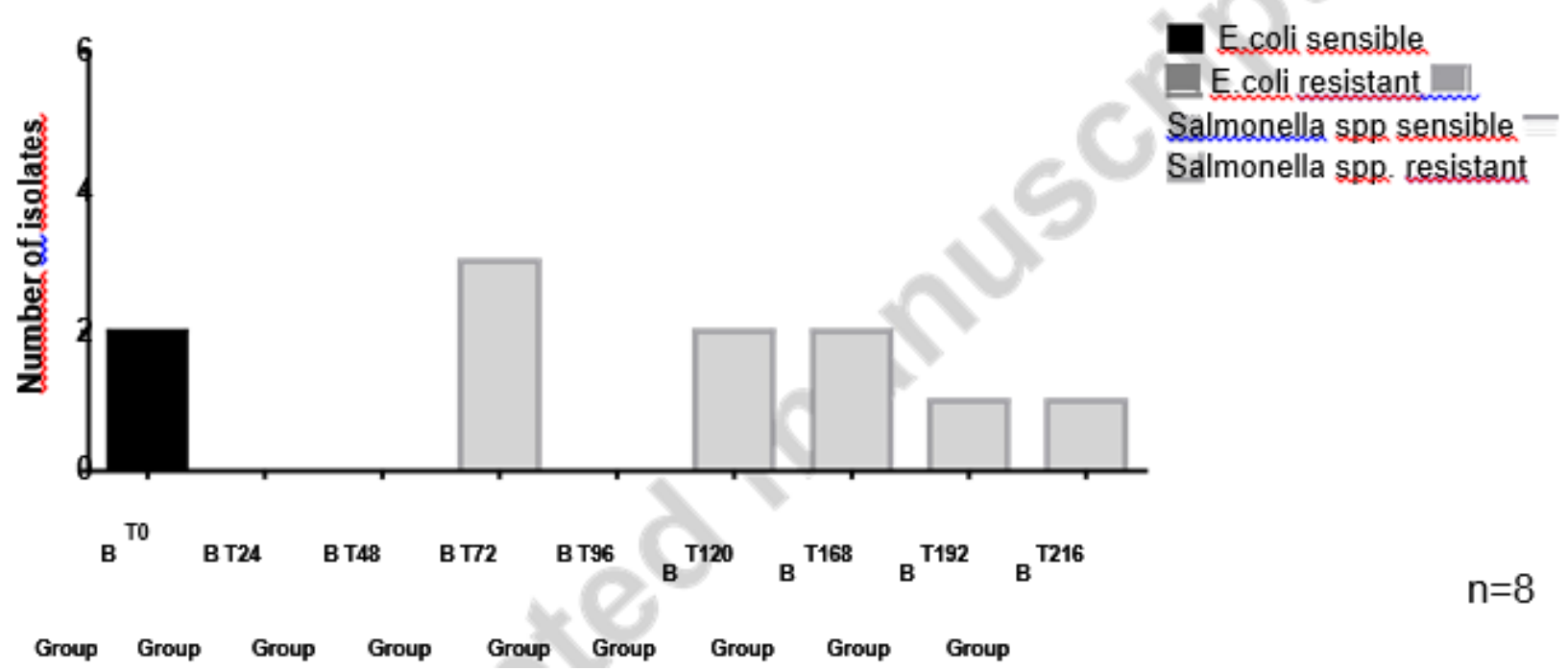

Fig.3: Distribution of isolated bacteria from cloacal swabs after single intracelomic administration of $2 \mathrm{mg} / \mathrm{kg}$ (Group B) of marbofloxacin in turtles (Trachemis scripta scripta). Bacterial sensitivity or resistance to marbofloxacin was test using Kirby - Bauer method $(n=8)$. 


\section{Kirby Bauer Group C (10mg/kg)}

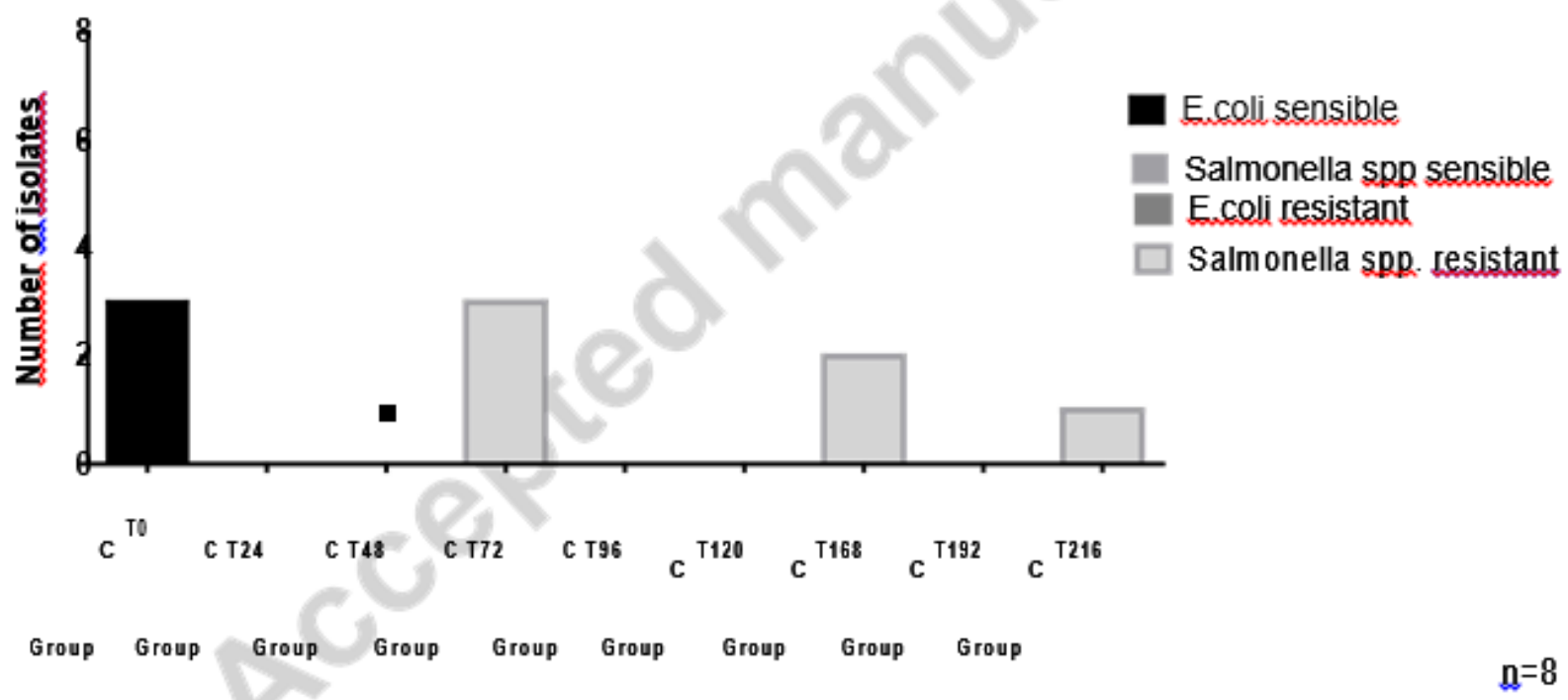

Fig.4: Distribution of isolated bacteria from cloacal swabs after single intracelomic administration of $10 \mathrm{mg} / \mathrm{kg}$ (Group C) of marbofloxacin in turtles (Trachemis scripta scripta). Bacterial sensitivity or resistance to marbofloxacin was test using Kirby - Bauer method $(n=8)$. The symbol a represents the death of two turtles $48 \mathrm{~h}$ after the drug administration: from that time point, $\mathrm{n}=6$ 


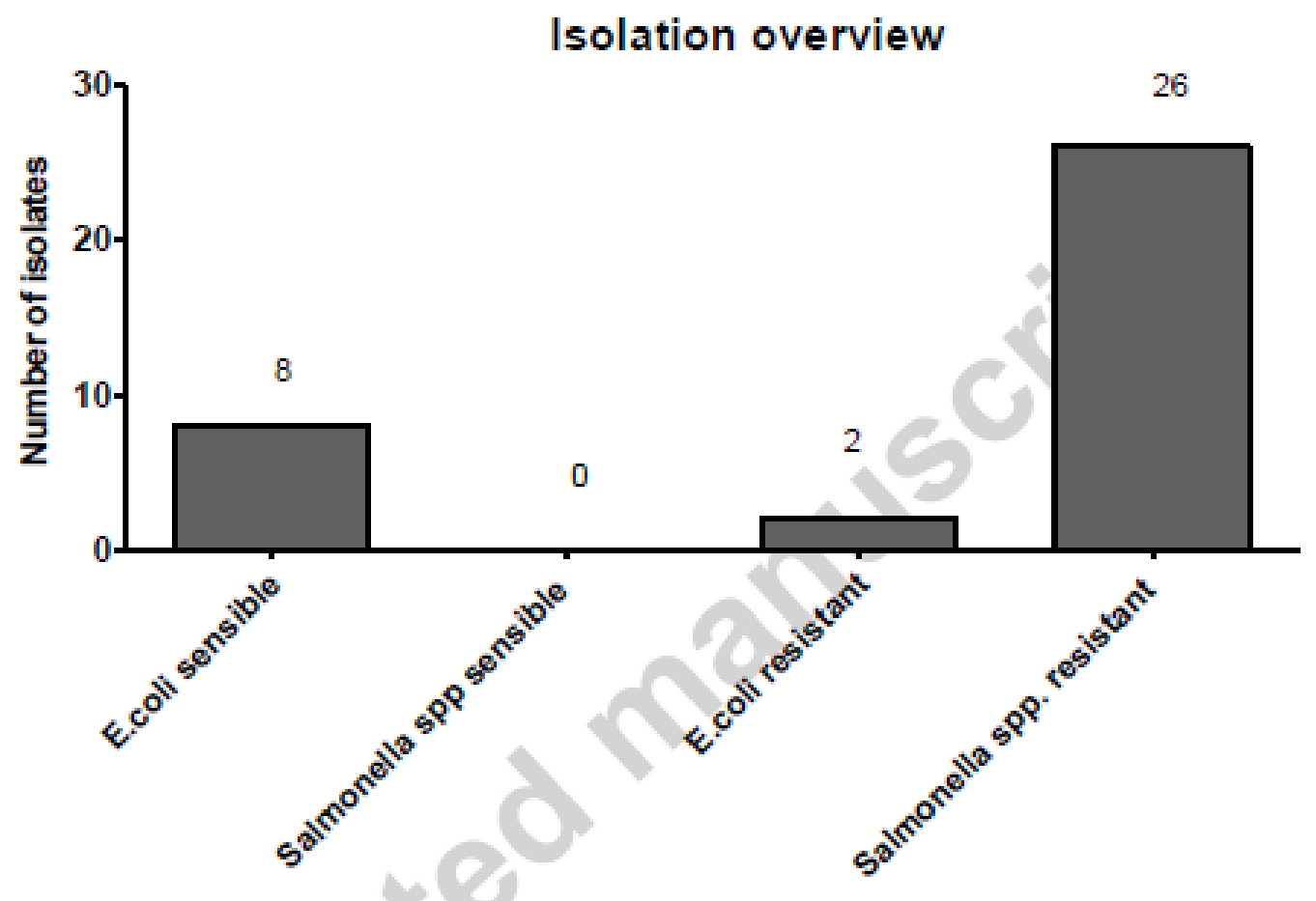

Fig.5: Total amount of each species of isolated bacteria and their sensitivity or resistancy to marbofloxacin using Kirby - Bauer method. 


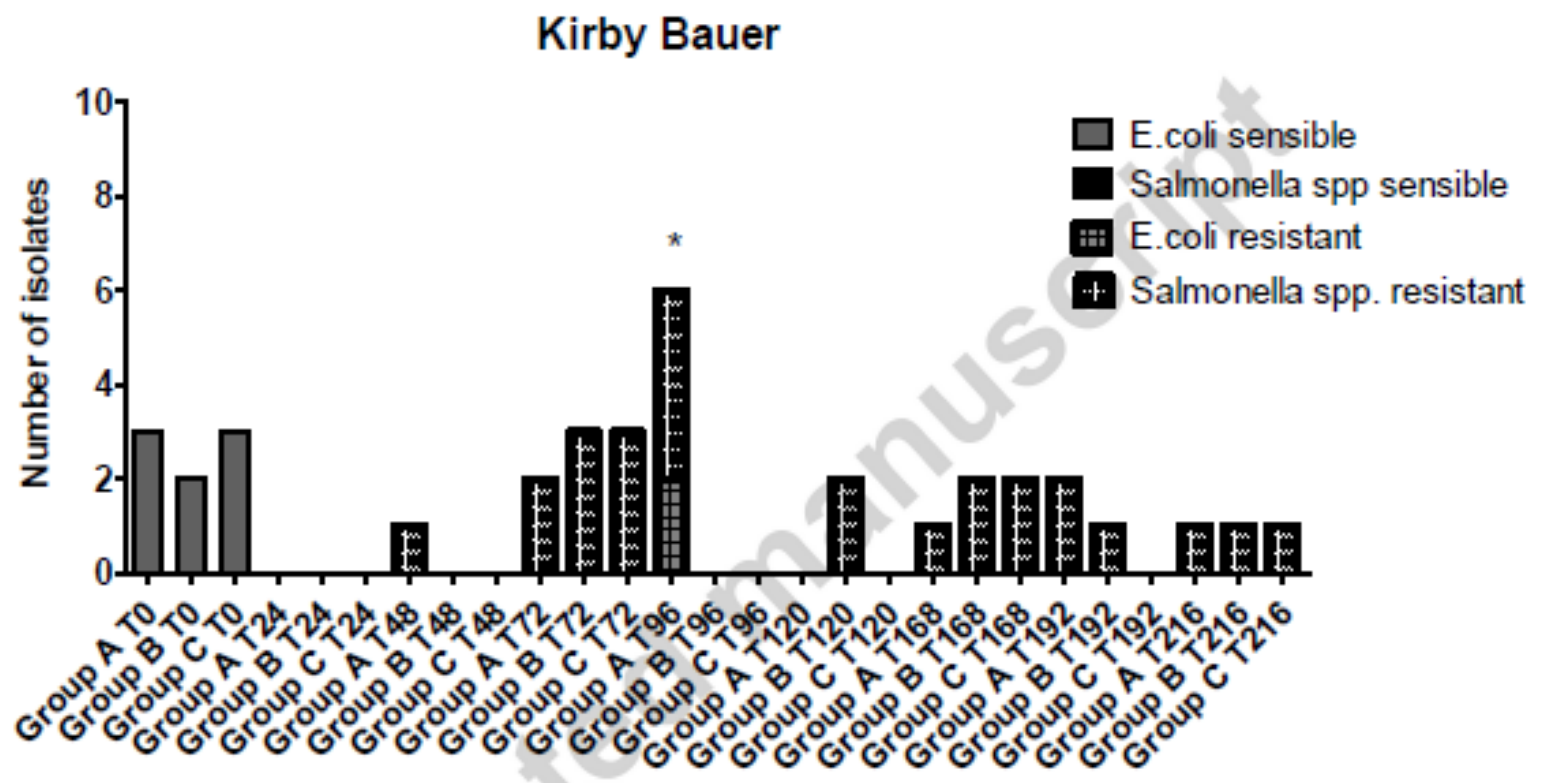

Fig.6: summary of all the isolated bacteria in each turtle group at each time point. Data were analysed using One way Anova with Dunnet post test $(P<0.05)$. Only Group A at T96 h demonstrated a significant stastically difference vs.s the other time points $(*)$. 